\title{
Grandmultiparity: The Reasons Women Give for High Parity in South-South Nigeria
}

\author{
Ikeanyi Eugene Maduabuchukwu*, Ibrahim Isa Ayuba \\ Department of Obstetrics and Gynecology, College of Health Sciences, Niger Delta University, Amassoma, Nigeria
}

Email address:

abuchikeanyi@yahoo.com (Ikeanyi E. M.)

${ }^{*}$ Corresponding author

To cite this article:

Ikeanyi Eugene Maduabuchukwu, Ibrahim Isa Ayuba. Grandmultiparity: The Reasons Women Give for High Parity in South-South Nigeria. Clinical Medicine Research. Vol. 6, No. 3, 2017, pp. 92-98. doi: 10.11648/j.cmr.20170603.16

Received: March 22, 2017; Accepted: April 1, 2017; Published: April 27, 2017

\begin{abstract}
Background: The Total Fertility Rates have declined below the replacement rates globally and in the industrialized countries. The rates are still high in Nigeria and most other poorer countries. Too much childbirth is associated with increased adverse obstetric outcomes and socioeconomic implications. There has been profuse literature on high parity but limited data on the reasons for high parity. We set out to explore the reasons the women have for high parity in Nigeria. Aim: To investigate the reasons women have for high parity in order to improve reproductive health services. Methods: This was a cross-sectional descriptive study on 288 grandmultiparas (para $\geq 5$ ) in South-south Nigeria between 2012 and 2016. EPI INFO software was used for analysis with statistical significance set at $\mathrm{P}<.05$. Results: The mean age of respondents was $35.3 \pm 4.2$ years. About $85 \%$ and $12 \%$ were in first marriage and remarried relationship respectively. The mean parity was $5.95 \pm 1.3$ and ranged 511 births. Respondents leading reasons for high parity were mistake (unplanned) $30.9 \%$, desire for specific gender $22 \%$ (male child $15.6 \%$ ) and personal desire for more children $15.3 \%$. Over $90 \%$ was aware of contraception, only $29.2 \%$ ever used any method. The younger $(\mathrm{OR}=4.9, \mathrm{P}=0.02)$, less educated $(\mathrm{OR}=0.39, \mathrm{P}=0.01)$ and employed $(\mathrm{OR}=0.23, \mathrm{P}=0.02)$ and $(\mathrm{OR}=6.9, \mathrm{P}=$ 0.04 ) respondents significantly cited spouse desire, desire of male child, child loss and contraception failure for high parity respectively. Conclusion: Mistake, desire for male child and large family were the leading reasons women gave for high parity. Maternal age, education and employment significantly influenced the reasons for high parity. There was high contraceptive awareness but poor utilization among the respondents; a huge unmet need of contraception in this population.
\end{abstract}

Keywords: Grandmultiparity, Reasons, High Parity, Contraception Uptake, Unmet Need

\section{Introduction}

In terms of obstetric performance the obstetric population can be classified into nullipara, primipara, multipara and grand multipara if they had nil, one, $\geq 2$ and $\geq 5$ previous pregnancies that terminated at $\geq 24$ completed weeks of gestation respectively. Parity of $\leq 4$ is considered low while $\geq 5$ is high parity or grandmultiparity.

High parity is globally one of the implicated risk factors for increased maternal and perinatal morbidity and mortality [1]. In Nigerian literatures, grandmultiparity contributes 35$38.4 \%$ of maternal deaths [2-3]. Areas of high fertility rates are known to have the highest concentrations of maternal deaths. This is true in sub-Saharan Africa known for virtually all settings for increased adverse obstetric outcome. Many women advertently or inadvertently have high parity of five or more deliveries. Unlike in industrialized economies with the prevalence of grand multiparity as low as 3-4\% [4], the values are as high as $17-33 \%$ in sub-Saharan Africa as in most other developing countries [5-8]. Obstetric, social and cultural reasons or ignorance either unilaterally or in combinations play role in this health behavior. In traditional African setting particularly sub Saharan sub region high premium is placed on large family. Male children are highly regarded mostly to maintain the patrilineal system traditional to most African nations. Failure of a wife to give birth to a male child or more irrespective of her number of female children not only threatens the marital harmony by attracting 
polygamy but may end in divorce. To forestall this, the woman continues to try to satisfy her spouse wish for male or more children.

The products of high parity population include high total fertility rates, high perinatal and maternal morbidity and mortality, socioeconomic stress to the family, health system and community.

Total fertility rate (TFR) in Nigeria as at 2013 was 5.5 births per woman within her reproductive years [9] relative to global rate of 2.42 children. TFR is a strong indicator of population change in a country. Rates of two children per woman are considered the replacement rate; the level at which a given generation can exactly replace itself; generally considered to be 2100 births per 1000 women [10]. This rate allows for a population relative stability in terms of total number. Rates below the replacement rate of two children indicate population decreasing in size and growing older. This is the fertility rate trend of global and industrialized economies of Western Europe and North America [10]. The total fertility rate; the estimated number of births over a woman's lifetime slightly rose to $1,862.5$ births per 1,000 women by 2014 in USA [10]. The contrary is true in the poorer nations like sub-Saharan African countries Nigeria inclusive with rates more than 5 children per woman [1]. Rates higher than two children indicate a population growing in size with a declining median age. The higher rates also indicate families' difficulties especially in feeding, children upbringing and education and for the woman to enter the labor force especially in poor resource countries.

There are diverse reasons for high parity in most developing countries as in sub-Saharan Africa. Among these are cultural need for large family and gender preference, unintended pregnancy mainly due to poor contraceptive services, high children loss and the desire to bear children for new spouse [5, 11-14]. This is unlike in industrialized economies with the lowest incidences of high parity attributable to good contraceptive services and accessibility, high literacy level, liberal abortion laws, standard and equitable health care system.

There has been extensive study with reports in the literature on increased adverse obstetric outcomes in high party $[1,15]$. Proportionally high rates of maternal death among grandmultipara have been reported from centers in Nigeria [2-3].

The paucity of data on the causes of high parity in our setting stimulated the interest in this study designed to investigate the reasons the obstetric population has for this reproductive health behavior. Evidence from this study will enhance focused reproductive health planning, education and services delivery. The data will also assist in refocusing prenatal counseling.

\section{Materials and Methods}

Niger Delta University Teaching Hospital (NDUTH), the study area is a tertiary hospital located at Okolobiri Bayelsa state; one of the oil rich regions of Southern Nigeria. The state is home to multiethnic groups with a population of about two million by 2005 estimate. The predominant ethnic groups are Izon, Ogbia and Nembe. Other residents are from other states across the country and other parts of the world. The main native occupation of the people are farming and fishing. Data for this cross-sectional descriptive study was prospectively raised between 2012 and 2016 on 288 women who were either currently pregnant attending prenatal care clinic or presented in labor after previous $\geq 5$ childbirths irrespective of the outcome. Relevant data were raised on the sociodemographic characteristics, family planning practices and their reasons for high parity. For the purpose of this study the reasons the women gave for high parity were broadly divided into unintended (mistake and failed contraception) and intended pregnancy related (couple, personal and spouse desire, change of spouse, desire for different genders, child loss). The data was collected by the researchers with the assistance of two trained resident doctors using semi structured pretested questionnaire. Each respondent was interviewed on one on one basis after counseling and obtaining consent from her. The sample size was based on formula $\left(n=z^{2} p q / d^{2}\right)$ by Cochrane WG [16], Where $p$ is the maximum known proportion of the relevant variable, here grand multiparity prevalence rate of $18.8 \%$ [17], $\mathrm{q}=1-\mathrm{p}$, $\mathrm{d}=$ Allowable error margin of estimate (precision of $5 \%$ ) $=$ $0.05, \mathrm{z}=$ this is $\mathrm{Z}$ statistic for $95 \%$ confidence level (value for selected alpha level $\alpha=0.05$ which is 1.96.) and $n=235$. This was further increased to 288 participants to further increase the power of the study. A delivery is any pregnancy that terminates after 24 completed weeks of gestation or birth weight of $\geq 500$ grams or born with sign of life. These were considered fetal viability by the World Health Organization (WHO). However in our setting like in other developing countries 28 completed weeks of gestation remains the cutoff point for fetal viability. A grand multipara is a woman who has had five or more previous deliveries. The World Health Organization defined high parity (HP) as five or more previous deliveries of gestation periods of $\geq 20$ weeks, and low parity (LP) as less than 5 previous deliveries with gestation periods of $\geq 20$ weeks $[15,18]$. The socioeconomic stratification of the participants was based on the woman's educational attainment; scored 0,1 and 2 for tertiary, secondary and primary/nil formal education respectively and male partner occupation; scored 1,2 and 3 for professional, middle level and unskilled level respectively [19]. Approval for the study was obtained from the hospital Research and Ethics Committee (REC). Each participant was counseled and verbal consent obtained for the study. All the eligible women who gave consent were recruited by purposive sampling as they first presented either at prenatal clinic or in labor at the labor ward. Confidentiality was ensured. Both those who had prenatal care and the unbooked were so included. The women that declined consent were excluded from the study. The data was collated and analyzed using EPI INFO Version 3.5.1 and INSTAT software. The statistical association of categorical variables was assessed as odds ratio with Fisher's exact test since some of the cells were $<5$. 
Univariate analyses of continuous variables are presented as frequencies, percentages, means and standard deviations and range. All statistical tests are two-sided and considered statistically significant at $\mathrm{p}<.05$ or $95 \%$ Confidence Interval (CI) values excluding the nullity of one. The interpretation of the Odd Ratio (OR) is as follows: OR $=1$ indicates no relationship between the predictor variable and the outcome variable; $\mathrm{OR}>1$ : indicates increased risk of the outcome i.e. predictor variable is a risk factor while $\mathrm{OR}<1$ indicates reduced risk of outcome, i.e. predictor variable is a protective factor.

\section{Results}

Table 1. Sociodemographic Characteristics of the Respondents $(N=288)$.

\begin{tabular}{|c|c|c|c|}
\hline Variable & Category & Number & Percentage \\
\hline \multirow{4}{*}{ Age } & $<30$ & 27 & 9.4 \\
\hline & $30-34$ & 95 & 33.0 \\
\hline & $35-39$ & 117 & 40.6 \\
\hline & $\geq 40$ & 49 & 17.0 \\
\hline \multirow{3}{*}{$\begin{array}{l}\text { Marital } \\
\text { Status }\end{array}$} & Unmarried & 9 & 3.0 \\
\hline & Married & 236 & 85.1 \\
\hline & Remarried & 32 & 11.8 \\
\hline \multirow{4}{*}{ Parity } & 5 & 146 & 50.7 \\
\hline & $6-7$ & 113 & 39.2 \\
\hline & $8-9$ & 19 & 6.6 \\
\hline & $\geq 10$ & 10 & 3.4 \\
\hline \multirow{4}{*}{ Education } & Nil & 11 & 3.8 \\
\hline & Primary & 70 & 24.3 \\
\hline & Secondary & 152 & 52.8 \\
\hline & Tertiary & 55 & 19.1 \\
\hline \multirow{2}{*}{ Occupation } & Employed & 236 & 81.9 \\
\hline & Unemployed & 52 & 18.1 \\
\hline \multirow{2}{*}{ Religion } & Christianity & 281 & 97.5 \\
\hline & Islam & 7 & 2.5 \\
\hline \multirow{5}{*}{ Social Class } & $\mathrm{i}$ & 5 & 1.7 \\
\hline & ii & 25 & 8.7 \\
\hline & iii & 97 & 33.7 \\
\hline & iv & 116 & 40.3 \\
\hline & $\mathrm{v}$ & 45 & 15.6 \\
\hline
\end{tabular}

Table 1 shows the sociodemographic characteristics of the respondents. The mean age of the respondents was $35.3 \pm 4.2$ with a range of 22-46 years. A smaller proportion, 122/288 $(42.4 \%)$ of the respondents was below 35 years of age while the majority, $57.6 \%$ was 35 years and above. A large proportion $40.6 \%$ was within 35-39 years age bracket. Approximately $85 \%$ of the participants were in their first marriage while $12 \%$ was at least in their second marital relationship and a small proportion $3.0 \%$ was unmarried at the time of the interview. A little more than half $(50.7 \%)$ of the respondents have had their fifth childbirth at the time of this interview while approximately $39 \%$ and $7.0 \%$ have respectively had their $6^{\text {th }}-7^{\text {th }}$ and $8^{\text {th }}-9^{\text {th }}$ childbirth and a small proportion $10 / 278(3.4 \%)$ has had at least their $10^{\text {th }}$ childbirth. About 4 of every 5 of the respondents were below or secondary level of education. Approximately $83 \%$ majority of the respondents were employed while the rest were not engaged in any gainful job. Among the employed respondents 49/288 (17.0\%) were government employed, 146 $(50.7 \%)$ were petty traders, $29(10.1 \%)$ were farmers and the others were either seamstresses $(2.8 \%)$ or hairdressers $(1.4 \%)$. One, three and six of every 10 of the respondents were of upper, middle and lower social class respectively.

Figure 1 is a display of the reasons the respondents gave for high parity. The leading reasons cited by the respondents for high parity were mistake (unplanned) $30.9 \%$, desire for male child $15.6 \%$, the women's personal desire for more children $15.3 \%$, contraceptive failure $10.1 \%$ and change of spouse about $9.0 \%$. When further aggregated, a majority; $170 / 288(59.0 \%)$ of the respondents high parity pregnancies were due to intended pregnancy-related reasons and 118 $(41.0 \%)$ were unintended pregnancy reasons. Culture driven offspring gender-related reasons was 63/288 (21.9\%) while desire for large family size (personal, spouse and couple desire) was 69/288 (24.0\%).

89

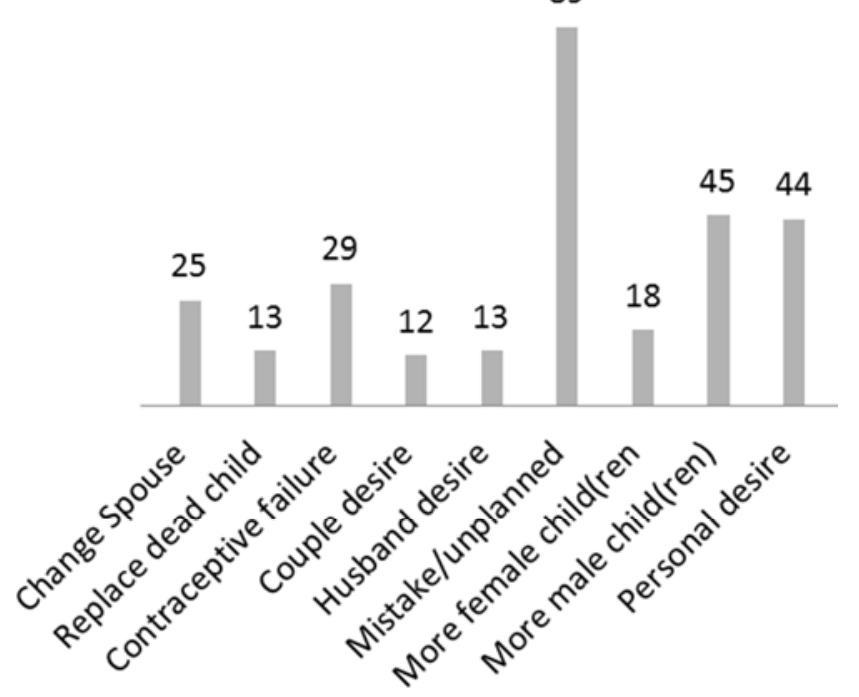

Figure 1. Reasons Participants Gave for High Parity $N=288$.

From Table 2 showing the reasons respondents gave for high parity cross-tabulated with respondents level of education, the respondents with lower level of education were significantly less likely to cite desire for male child as a reason for high parity $(\mathrm{P}<0.01)$. Both arms were similar in other cited reasons for high parity. The respondents with low level of education were also more likely to have high parity due to change of spouse, mistake as well as personal desire. However; the observed differences were not statistically significant. 
Table 2. Reasons the Women Gave for High Parity vs. Participants' Educational Attainment N=288 Participants.

\begin{tabular}{lllll}
\hline \multirow{2}{*}{ Reason } & \multicolumn{1}{c}{ Educational Attainment } & \multirow{2}{*}{ OR $(\mathbf{9 5 \%} \mathbf{C I})$} & P-value \\
\cline { 2 - 4 } & $\mathbf{S 2}^{\mathbf{0}}$ level, $\mathbf{n}=\mathbf{2 3 3}$ & $\mathbf{> 2}^{\mathbf{0}}$ level, $\mathbf{n}=\mathbf{5 5}$ & $1.26(0.42-3.84)$ & 0.80 \\
\hline Change Spouse & $21(9.0)$ & $4(7.3)$ & - & - \\
Child (ren) death & $13(5.6)$ & $0(0.0)$ & $0.58(0.24-1.39)$ & 0.22 \\
Contraceptive failure & $21(9.0)$ & $8(14.5)$ & $1.19(0.25-5.59)$ & 1.00 \\
Couple desire & $10(4.3)$ & $2(3.6)$ & - & - \\
Husband desire & $13(5.6)$ & $0(0.0)$ & $1.11(0.58-2.12)$ & 0.87 \\
Mistake/unplanned & $73(31.3)$ & $16(29.1)$ & $1.19(0.33-4.27)$ & 1.00 \\
Desire female & $15(6.4)$ & $3(5.5)$ & $0.39(0.19-0.80)$ & 0.013 \\
Desire male & $30(12.9)$ & $15(27.3)$ & $1.29(0.54-3.08)$ & 0.68 \\
Personal desire & $37(15.9)$ & $7(12.7)$ & & \\
\hline
\end{tabular}

Table 3 is the display of the respondents' awareness and utilization of modern contraception cross-tabulated by unintended pregnancy. A large number 260/288 (90.3\%) of the respondents were aware of modern contraception. A larger proportion $112 / 118(94.9 \%)$ of the respondents that cited unintended pregnancy as a reason for high parity compared with $148 / 170(87.1 \%)$ who cited planned pregnancy was aware of modern contraception $(\mathrm{OR}=2.78$,
$95 \%$ CI: $1.09,7.07, \mathrm{P}=0.03)$. A minority $84 / 288(29.2 \%)$ of the respondents had ever used a modern contraception. A significant majority $(39.8 \%$ vs. $21.8 \%, \mathrm{P}=0.002)$ of the respondents that cited unintended pregnancy for high parity had ever used any form of modern contraception. The most used types of contraception by the respondents were the Injectable $40 / 86(46.5 \%)$ and oral $25 / 86 \quad(29.1 \%)$ contraception.

Table 3. Respondents Contraceptive Awareness and Previous Utilization Cross-tabulated with Unintended Pregnancy N=288.

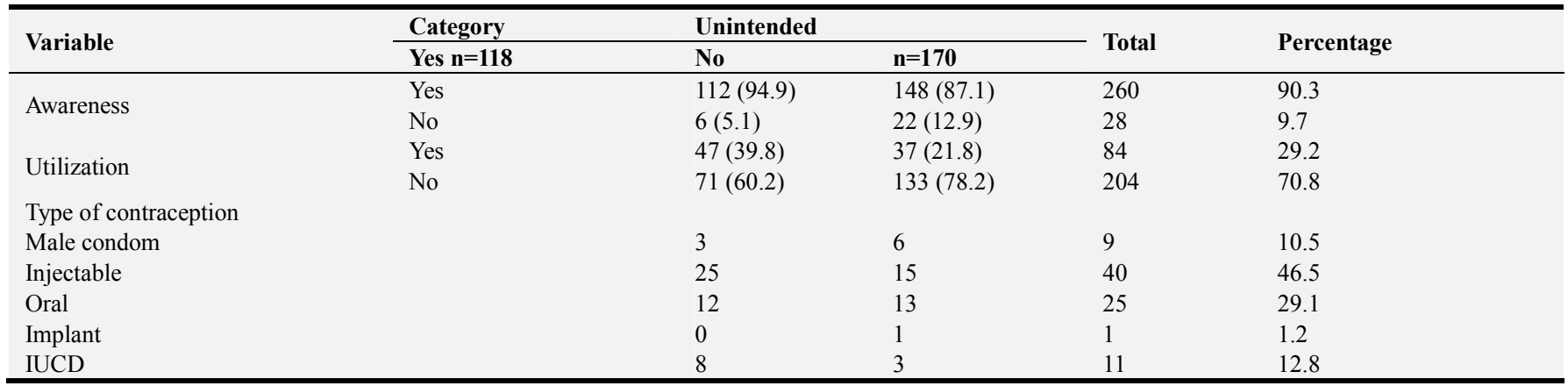

Table 4 shows reasons respondents gave for high parity stratified by age. The respondents younger than 35 years of age were significantly about fivefold more likely to cite spouse desire for more children for high parity compared with the older respondents $(\mathrm{P}<0.02)$. The younger respondents were however, less likely to cite change of spouse (5.0\% vs. $12.0 \%)$ and couple desire (2.5\% vs. $5.7 \%)$ for high parity. The younger respondents were $20-60 \%$ more likely to give mistake, personal desire, desire for more female and child loss as reasons for high parity. However, none of the observed differences was statistically significant $(\mathrm{P}>$.05).

Table 4. Reasons the Respondents Gave for High Parity Cross-tabulated by Age of Respondents $n=288$.

\begin{tabular}{|c|c|c|c|c|}
\hline \multirow[b]{2}{*}{ Variable } & \multicolumn{2}{|l|}{ Age (yrs) } & \multirow{2}{*}{ Odd Ratio (95\% CI) } & \multirow{2}{*}{ P-value } \\
\hline & $<35(n=122)$ & $\geq 35(n=166)$ & & \\
\hline Change Spouse & $6(4.9)$ & 19 (11.4) & $0.40(0.15-1.04)$ & 0.06 \\
\hline Child (ren) death & $6(4.9)$ & $7(4.2)$ & $1.18(0.38-3.59)$ & 0.78 \\
\hline Contraceptive failure & $9(7.4)$ & $20(12.0)$ & $0.58(0.26-1.33)$ & 0.24 \\
\hline Couple desire & $3(2.5)$ & $9(5.4)$ & $0.44(0.12-1.66)$ & 0.25 \\
\hline Husband desire & $10(8.2)$ & $3(1.8)$ & $4.9(1.31-18.03)$ & 0.02 \\
\hline Mistake/unplanned & $40(32.8)$ & 49 (29.5) & $1.17(0.70-1.93)$ & 0.61 \\
\hline Desire female & $9(7.4)$ & $9(5.4)$ & $1.39(0.53-3.61)$ & 0.62 \\
\hline Desire male & $17(13.9)$ & $28(16.9)$ & $0.80(0.41-1.54)$ & 0.52 \\
\hline Personal desire & $22(18.0)$ & $22(13.3)$ & $1.44(0.76-2.74)$ & 0.32 \\
\hline
\end{tabular}

The respondents in employment were about sevenfold more likely to cite contraceptive failure and about $80 \%$ less likely to cite child loss for high parity. The observed differences were statistically significant. This is shown on Table 5 displaying reasons women gave for high parity stratified by employment status. From the Table also, the employed respondents were less likely to give change of spouse and spouse desire as a reason for high parity. However, none of the observed differences was statistically significant. 
Table 5. Reasons the Women gave for High Parity Cross-tabulated by Employment Status $n=288$.

\begin{tabular}{lllll}
\hline Variable & Employment & & OR (95\% CI) & P-value \\
\hline & Yes n=236 & No n=52 & & 0.42 \\
\hline Change Spouse & $19(8.1)$ & $6(11.5)$ & $0.67(0.25-1.77)$ & 0.02 \\
Child (ren) death & $7(3.0)$ & $6(11.5)$ & $0.23(0.08-0.73)$ & 0.04 \\
Contraceptive failure & $28(11.9)$ & $1(1.9)$ & $6.9(0.91-51.68)$ & - \\
Couple desire & $12(5.1)$ & $0(0.0)$ & - & 0.26 \\
Partner desire & $9(3.8)$ & $4(7.7)$ & $0.48(0.14-1.61)$ & 0.87 \\
Mistake/unplanned & $74(31.4)$ & $15(28.8)$ & $1.13(0.58-2.18)$ & 1.00 \\
Desire female & $15(6.4)$ & $3(5.8)$ & $1.11(0.31-3.98)$ & 0.83 \\
Desire male & $38(16.1)$ & $7(13.5)$ & $1.23(0.52-2.94)$ & 0.40 \\
Personal desire & $34(14.4)$ & $10(19.2)$ & $0.71(0.32-1.54)$ & \\
\hline
\end{tabular}

When the reasons the respondents gave for high parity were stratified by marital status, the unmarried grandmultiparas were about sevenfold and twice more likely to cite partner desire and mistake for high parity respectively. None of the observed differences was significant. Other variables were too few for statistical comparison.

Compared with the respondents of lower social class, the upper class counterparts were less likely to cite children loss or male partners' wish $(0.0 \%$ vs. $5.0 \%)$ respectively for high parity. The upper class subset was about thrice more likely to attribute their high parity to contraceptive failure and about twice to desire for male children. None of the observed differences was significant.

\section{Discussion}

The main findings in our study were that culture related reasons of desire for large family size (24.0\%) and specific offspring gender $(22.0 \%)$ accounted for $46 \%$ while unintended pregnancy related reasons went for $41 \%$ of the reasons for high parity in this study. Change of spouse accounted for $8.7 \%$ and replacement of dead child (ren) went for $4.5 \%$ of the reasons for high parity in our data. In addition, there was high level of awareness (90.3\%) but low uptake (29.2\%) of modern contraception among grand multiparous women in this data. Most of the respondents were of low literacy, social status and lacked gainful employment.

When disaggregated, our data indicates that mistake (30.9\%) was the leading reason given by the respondents for grand multiparity. This was much higher than $18.4 \%$ reported by other researchers [8]. This was followed by the desire for specific gender $22.0 \%$ which is comparable to $19.7 \%$ reported in a comparable study [11]. Replacement of dead children accounted for $4.5 \%$ of the reasons for high parity in our study unlike $15.4-28.8 \%$ reported by other researchers [5, 11]. About a quarter of the respondents cited the desire for more children as the reasons for high parity in our data. This is comparable to a report [5] and lower than $33.3 \%$ reported in another study [11]. From our data the cultural drive of desire for specific offspring gender; more often male children and large family size was responsible for $46 \%$ of the reasons for high parity in this study. This compares favorably with the reports by Adeniran et al in Ilorin that cited culture related factors of desire for large families and specific gender among the offspring to be responsible for $53 \%$ of pregnancies in grandmultipara in their study [11]. The cultural influence was not attenuated by educational attainment of the participants in our data $(\mathrm{P}=0.76)$. Patrilineal culture is strong in Nigeria as in most other African countries. In addition, most of the respondents were of low literacy and social class mostly on self employed petty trading and agrarian activities requiring help from their children who in most cases help in hawking or in subsistent farming activities.

The mean age of the participants was $35.3 \pm 4.2$ years and $40.6 \%$ was within $35-39$ years age group. Unlike the older respondents, the younger group significantly about five folds cited male partners wish for more children for their high parity. Compared with the older female partners, the younger women are expected to have less capacity for negotiating family size with their male partners. Eighty one percent of the respondents were of low literacy level. Educational attainment of the respondents influenced their reason for high parity. Participants of low literacy were significantly less likely to cite desire for male child for their high parity. Approximately $82.0 \%$ of the respondents were in some forms of employment with $17 \%$ and $65 \%$ of them in government and self employment respectively. The majority of the subjects were either unemployed or in self employment; mostly petty trading and subsistent farming. In addition, close to $90 \%$ of the respondents was from lower socioeconomic class. This corroborates the poor financial empowerment among the high parity women. High rate of Low literacy and low social class have been previously associated with grandmultiparity $[5,11,14]$. Low literacy, poverty and ignorance are risk factors for lack or poor utilization of contraception and consequent unintended pregnancy and high parity. Respondents from upper social class were less likely to cite child loss and male partner wish for high parity. Parental social status is expected to influence child survival. In less social deprivation, there are improved environmental standards, quality nutrition and health seeking behaviors that allow quality health and survival. In addition, the upper social class subset was about thrice more likely to attribute their high parity to contraceptive failure and about twice to desire for male child. Accessibility and affordability of modern contraception is more with empowered women. These are equally the women that are more likely to desire more male children either for the cultural reason of 
maintaining the family lineage or matrimonial harmony. Most; $97.0 \%$ of the respondents were in marriage at the time of the study. The unmarried proportion was too low for any meaningful comparative statistics. In all, unintended pregnancy rate of $41 \%$ among the respondents was high. There has been previous documented evidence of association of high parity with unintended pregnancy [20-21]. The contraceptive awareness among the respondents was $90.3 \%$ but the uptake was $29.2 \%$. There was a high level of modern contraceptive awareness but low service utilization among the respondents. Non uptake or inconsistent use of contraception has been associated with increased unintended pregnancy and therefore high parity [21]. Contraception is an established means of delaying and limiting childbirth. The level of awareness was comparable to $90.9-97.1 \%$ reported in similar studies $[5,11]$. The uptake was however lower than $44.9 \%$ by Idoko et al [5] and higher than $6.4 \%$ by Adeniran et al [11]. The latter study was in the north central Nigeria with increased religious bias to modern contraception. Compared with the subset that had intended pregnancy, the subset that cited unintended pregnancy for grand multiparity was more aware $(94.9 \%$ vs. $87.1 \%)$ and had higher uptake $(39.8 \%$ vs. $21.8 \%)$ of contraception than those that had planned pregnancies. This further corroborates the inconsistent use, wrong use and method inherent failure as the possible reasons for increased rates of unintended pregnancy among contraceptive users in this study. Contraception is one of the recognized means of preventing high parity and advanced maternal age births yet a significant proportion of the participants that cited unintended pregnancy for their high parity did not adequately avail themselves of this contraceptive benefit.

The cross sectional design of this study is weak in the proof of causality. However the study relied on its prospective data that is known to be good in the data reliability and completeness. Random sampling is superior in bias control relative to purposive sampling method that was used in this study. Data from a community survey will be more generalizable than a hospital based data as in this study.

\section{Conclusion}

Cultural desire for large families and preference for male gender offspring coupled with unintended pregnancy related causes drove the high parity observed in this population. Refocused prenatal health education, women empowerment and renewed contraception services will go a long way in reducing the prevalence of grand multiparty in this setting.

\section{References}

[1] Mgaya AH, Massawe SN, Kidanto HL, Mgaya HN. Grand multiparity: is it still a risk in pregnancy? BMC Pregnancy Childbirth. 2013; 13: 241.

[2] Adetoro OO, Okwereku FO. Maternal mortality at Ilorin, Nigeria. Trop J Obstet Gynecol. 1988; 1: 18-22.
[3] Gharoro EP, Igbafe AA. Grandmultiparity: Emerging trend in a tropical Community. Trop J Obstet Gynecol. 2001; 18: 2730 .

[4] WHO. WHO Report. Geneva: WHO; 2004. Available from: http://www.int/whr/2004/annex/country/can/en/

[5] Patrick Idoko, Glenda Nkeng, Matthew Anyawu. Reasons for current pregnancy amongst grand multiparous Gambian women - a cross sectional survey. BMC Pregnancy and Childbirth 2016; 16: 217 DOI 10.1186/s12884-016-1016-7.

[6] Geidam AD, Audu BM, OummateZ. Pregnancy outcome among grand multiparous women at the University of Maiduguri Teaching Hospital: a case control study. J Obstet Gynaecol. 2011; $31 \quad$ (5): 404-8. Doi: 10.3109/01443615.2011.561383.

[7] Hoque M, Hoque E, Kader SB. Pregnancy complications of Grandmultiparity at a rural setting of South Africa. Iran J Reprod Med. 2008; 6 (1): 25-31.

[8] Yasir R, Perveen FZ, Ali L, Perveen S, Tayyab S. Grandmultiparity still an obstetric risk for developing countries. Med Channel. 2010; 16: 264-8.

[9] Nigeria Demographic and Health Survey 2013. Preliminary Report. National Population Commission (NPC). Abuja, Nigeria. MEASURE DHS, ICF International Calverton, Maryland, USA. 2013.

[10] Hamilton BE, Martin JA, Osterman MJ, Curtin SC, Mathews TJ. Births: Final Data for 2014. Natl Vital Stat Rep. 2015; 64 (12): 1-64.

[11] Adeniran AS, Fawole AA, Fakeye OO. Grandmultiparity: Reasons for index pregnancy, contraception and relationship to the Millennium Development Goals. East and Central African Medical Journal 2014; 1 (1): 3-7.

[12] Roman H, Robillard PY, VerspyckE, HulseyTC, MarpeauL, BarauG. Obstetric and neonatal outcomes in Grandmultiparity. ObstetGynecol 2004; 13 (6): 1294-1299. (Pubmed).

[13] Obiechina NJA, Ugboaja JO, Ezeama CO. Grand multiparity: reasons for the index pregnancy. Trop $J$ Med Res. 2008; 12 (2): 65-70.

[14] Kuti O, Dare FO, Oguniyi SO. Grand multiparity: Mothers own reasons for the index pregnanc. Trop J Obstet Gynaecol. 2001; 18 (1): 34-7.

[15] Yahya M Al-Farsi, Daniel R Brooks, Martha M Werler, Howard J Cabral, Mohammed A Al-Shafei, Henk C Wallenburg. Effect of high parity on occurrence of anemia in pregnancy: a cohort study. BMC Pregnancy and Childbirth 2011; 11: 7/DOI: 10.1186/1471-2393-11-7.

[16] Cochrane W. G, editor. Sampling Techniques. $3^{\text {rd }}$ ed. New York: John Wiley \& sons; 1977.

[17] GeidamAD, AuduBM, OummateZ. Pregnancy outcome among grand multiparous women at the University of Maiduguri Teaching Hospital: a case control study. $J$ ObstetGynaecol. 2011; $31 \quad$ (5): 404-8. Doi: $10.3109 / 01443615.2011 .561383$.

[18] HumphryMD. Is grand multiparty an independent predictor of pregnancy risk? A retrospective observational study. Med. $J$ Aust 2003; 179 (6): 294-6. 
[19] Olusanya O. Okpere EE. Ezimokhai M. The importance of social class in voluntary fertility control in a developing country. West Afr Journal of medicine1985; 4: 205-212.

[20] Belayneh H, Abebe G, Tizta T. Unwanted pregnancy and associated factors among pregnant 339 married women in Hosanna Town, Southern Ethiopia. PLoS One 2012; 7 (6): e39074. doi: 10.1371/journal. pone.0039074.
[21] Gilda Sedgh, Akinrinola Bankole, Boniface Oye-Adeniran, Isaac F. Adewole, SusheelaSingh, RubinaHussain. Unwanted pregnancy and Associated Factors Among Nigerian Women. Perspectives on Sexual and Reproductive Health Guttmacher Institute 2006; 32 (4): 175-184. 